\title{
PRODUÇÃO DE MUDAS DE MARACUJAZEIRO-AMARELO POR ENXERTIA HIPOCOTILEDONAR SOBRE SETE ESPÉCIES DE PASSIFLORAS ${ }^{1}$
}

\author{
GERALDO COSTA NOGUEIRA FILHO ${ }^{2}$, GIVANILDO RONCATTO ${ }^{3}$, CARLOS RUGGIERO ${ }^{4}$, \\ JOÃO CARLOS DE OLIVEIRA ${ }^{4}$, EUCLIDES BRAGA MALHEIROS ${ }^{4}$
}

RESUMO - O maracujazeiro-amarelo (Passiflora edulis Sims. f. flavicarpa Deg.) é a principal Passifloraceae cultivada no Brasil, e seu cultivo tem encontrado algumas dificuldades, principalmente no que concerne à longevidade dos pomares, a qual tem sido reduzida devido à incidência de doenças e nematoides que atacam o seu sistema radicular. Este trabalho teve por objetivo estabelecer tecnologias para a produção de mudas de maracujazeiro-amarelo, através da enxertia hipocotiledonar, sobre sete porta-enxertos. Os porta-enxertos utilizados foram: P. edulis f. flavicarpa; P. caerulea; P. alata; P. gibertii; P. coccinea; P. cincinnata e P. setacea. $\mathrm{O}$ delineamento experimental foi o inteiramente casualizado, com 36 repetições para cada porta-enxerto. As características avaliadas foram: percentual de sobrevivência dos enxertos, altura das plantas, número de folhas, diâmetro do porta-enxerto. A metodologia de enxertia hipocotiledonar testada foi bem-sucedida para a maioria das espécies testadas. Destacaram-se os porta-enxertos: P. caerulea; $P$. gibertii; $P$. cincinnata e $P$. flavicarpa, tanto pelo alto índice de pegamento como pela precocidade na obtenção da muda.

Termos para Indexação: Passiflora spp., propagação vegetativa, microenxertia, compatibilidade, enxertia de mesa, metodologia.

\section{SEEDLING PRODUCTION OF YELLOW PASSION FRUIT BY HYPOCOTYLEDONARY GRAFTING ON SEVEN SPECIES ON PASSIFLORAS}

\begin{abstract}
The yellow passion fruit (Passiflora edulis Sims f. flavicarpa Deg.) Passifloraceae is the main crop in Brazil, and the crop has found some difficulties, particularly concerned to the orchards longevity, which has been reduced due to diseases and nematodes that attack the root system. This study was carried out to establish technologies for the production of seedlings of yellow passion fruit by hypocotyledonary grafting on seven rootstocks. The treatments used as rootstocks were: $P$. edulis f. flavicarpa, $P$. caerulea, $P$. alata, $P$. giberti, $P$. coccinea, $P$. cincinnata and $P$. setacea. The experimental design was completely randomized, with 36 replications for each rootstock. The percentage of graft survival, plant height, number of leaves and rootstock diameter were the characteristics evaluated. The hypocotyledonary grafting methodology was successful for most species tested. P. caerulea, P. giberti, P. cincinnata and P. flavicarpa were the stood out rootstocks by their high conditions of plants growth, and by their early plants production.

Index terms: Passiflora spp.; vegetative propagation; micrografting; compatibility; table grafting; methodology.
\end{abstract}

\footnotetext{
${ }_{1}^{1}$ (Trabalho 021-10). Recebido em: 05-01-2010. Aceito para publicação em: 16-10-2010.

${ }^{2}$ In memoriam.

${ }^{3}$ Pesquisador A da Embrapa Mato Grosso. Avenida das Itaúbas, 3257 - Setor Comercial, Cep 78550-194, Sinop - MT. E-mail: givanildoroncatto@ig.com.br

${ }^{4}$ Professores Titulares da Unesp/Fcav. Via de acesso Paulo Donato Castellane, s/n Cep 14884-900 Jaboticabal-SP. E-mails: ruggiero@fcav.unesp.br; jocaoliv@fcav.unesp.br; euclides@fcav.unesp.br
} 


\section{INTRODUÇÃO}

A cultura do maracujazeiro (Passifiora edulis Sims. f. flavicarpa Deg.) é difundida nas regiões tropicais do mundo, e sua pouca longevidade em cultivo é um grave problema para os produtores, já destacava Delanoë (1991). O maracujazeiro pode ser propagado por sementes, estaquia e enxertia. No Havaí, Brasil, Sri Lanka, Quênia e Nova Zelândia, a produção comercial é baseada em plantas de maracujazeiro-amarelo ou roxo propagadas por sementes. Em contraste com a Austrália, onde a indústria explora híbridos entre os dois tipos de maracujazeiro (amarelo e roxo) e onde características particulares dos porta-enxertos são favorecidas, a enxertia é utilizada como a principal forma de propagação (MENZEL et al., 1989).

A propagação do maracujazeiro-amarelo no Brasil é feita basicamente através de sementes, havendo segregação e, consequentemente, existência de indivíduos diferentes (STENZEL; CARVALHO, 1992), existindo nesta espécie alta variabilidade, decorrente da desuniformidade de plantas nos pomares. Desse modo, a propagação vegetativa apresenta vantagens na manutenção de materiais com boas características agronômicas, favorecendo a multiplicação de plantas produtivas e tolerantes às pragas e doenças (LIMA et al., 1999).

As doenças provocadas por patógenos do solo em maracujazeiro constituem-se em um dos principais problemas para essa cultura no Brasil. A alternativa de controle dessas doenças seria a utilização de porta-enxertos resistentes. Várias espécies de passifloras nativas vêm apresentando resistência a essas doenças, mas sua utilização como porta-enxertos, oriundos de sementes, tem sido dificultada pelas diferenças de espessura e a forma (cilíndrica ou quadrangular) entre o porta-enxerto e o enxerto da espécie comercial (CHAVES et al., 2003). Para resolver essa incompatibilidade de diâmetro entre as peças envolvidas na enxertia, Kimura (1994) preconizou o uso da enxertia hipocotiledonar de plântulas de maracujazeiro como um processo viável.

Este trabalho teve por objetivo estabelecer tecnologias para a produção de mudas de maracujazeiro-amarelo, através da enxertia hipocotiledonar, sobre sete espécies de passifloras com potencial uso como porta-enxertos.

\section{MATERIAL E MÉTODOS}

$\mathrm{O}$ experimento foi realizado em casa de vegetação e Ripado de fruticultura do Departamento de Produção Vegetal da Faculdade de Ciências
Agrárias e Veterinárias de Jaboticabal - Universidade Estadual Paulista (FCAV-UNESP), no período de 30 de outubro de 2001 a 02 de abril de 2002.

A variedade-copa utilizada para todos os tratamentos foi o maracujazeiro-amarelo 'FB 200', do viveiro Flora Brasil (Araguari - MG), e as espécies de passifloras como potenciais porta-enxertos foram Passiflora edulis f. flavicarpa; P. caerulea; P. alata, $P$. gibertii; P. coccinea; $P$. cincinnata; $P$. setacea (sete tratamentos). Foi utilizado o delineamento experimental inteiramente casualizado, com 36 repetições por tratamento, em esquema fatorial para as espécies de passifloras potenciais porta-enxertos e as datas de avaliação e uma planta como parcela experimental.

Foram realizadas duas semeaduras para a obtenção dos porta-enxertos. Na primeira (30-102001), utilizaram-se 100 sementes de cada portaenxerto sem qualquer tratamento prévio. Na segunda (07-12-2001), 120 sementes de cada porta-enxerto, previamente embebidas em água destilada por cerca de doze horas e, posteriormente, semeadas em bandejas plásticas com substrato comercial Plantmax para hortaliças, composto por uma mistura de casca de Pinus, vermiculita e carvão ativado, na proporção de 3:1:1 (v:v). Da mesma forma, foram produzidos os "seedlings" de maracujazeiro-amarelo para fornecimento dos garfos, semeando-se a cada semana 100 sementes em uma bandeja, durante sete semanas.

O método de enxertia utilizado foi o de fenda cheia no topo hipocotiledonar. Quando os portaenxertos e enxertos atingiram a fase de enxertia, cerca de 6 a $8 \mathrm{~cm}$ de altura e uma a duas folhas definitivas, o que ocorreu com cerca de 30 dias após a semeadura para as espécies mais precoces ou vigorosas e 90 dias para as de crescimento mais lento, realizou-se a enxertia. Umedeceu-se previamente o substrato do porta-enxerto de forma a retirá-lo com um mínimo de danos ao seu sistema radicular. Então, decepouse o mesmo abaixo dos cotilédones e abriu-se uma fenda longitudinal $(1,0 \mathrm{~cm})$. Procedeu-se à retirada do garfo, decepando-se a plântula doadora abaixo dos cotilédones e fez-se uma cunha em bisel duplo de forma a expor os tecidos do câmbio, utilizando-se, para isso, de uma lâmina de platina. Então, juntaramse enxerto e porta-enxerto com cuidado para fazer-se coincidirem os tecidos cambiais e utilizou-se de fita adesiva (crepe) para envolver a região da enxertia, protegendo-a, evitando o seu ressecamento, assim como o excesso de umidade, e funcionando também como tutor da muda.

Imediatamente após a realização da enxertia propriamente dita, a muda já enxertada foi transplantada em copo plástico $(200 \mathrm{~mL})$ 
com o mesmo substrato utilizado anteriormente. Já transplantada, a muda foi tutorada por uma estaquinha de madeira $(18 \mathrm{~cm})$ e coberta com um saco plástico transparente $(15 \times 20 \mathrm{~cm})$, que foi preso com um elástico para formar uma câmara úmida. Posteriormente, as mudas foram colocadas em bandeja plástica com uma lâmina de cerca de 1,0 $\mathrm{cm}$ de água e deixadas à sombra, no ripado. Aos dez dias, retirou-se o elástico e, aos quinze, removeu-se o saco plástico; aos vinte dias, foram levadas para uma zona limítrofe entre a sombra e a meia-sombra; aos vinte e cinco dias, foram retiradas das bandejas, e aos trinta dias, foram levadas para o ambiente de meia-sombra do ripado.

Enquanto ainda nas bandejas, a água era reposta sempre que necessário. Após deixarem as bandejas, as mudas foram regadas diariamente com o sistema de microaspersores colocado junto à cobertura do ripado. A cada quinze dias, as mudas eram regadas com uma solução de 10 gotas por litro de água do produto comercial Ouro-verde $(\mathrm{N} 6 \%$, $\mathrm{P}_{2} \mathrm{O}_{5} 6 \%, \mathrm{~K}_{2} \mathrm{O} 8 \%$, Mg 0,5\%, S 0,5\%, B 0,03\%, Zn $0,05 \%$, Fe $0,1 \%$, Mn 0,03\%), fertilizante líquido.

As características avaliadas foram: $1-\mathrm{O}$ percentual de germinação foi avaliado através de contagem semanal das plântulas germinadas. Esta contagem foi iniciada 30 dias após a primeira semeadura e 08 dias após a segunda. 2 - A sobrevivência (\%) foi observada através de contagem nos primeiros 30 dias, em intervalos de 5 dias após a enxertia, e aos 45 e 60 dias. 3 - A altura das plantas foi mensurada, utilizando régua com $1,0 \mathrm{~mm}$ de precisão, medindose a planta do colo ao ápice, aos $0 ; 30 ; 45$ e 60 dias após a realização da enxertia. 4- O número de folhas foi realizado obtido pela contagem das mesmas, aos $0 ; 30 ; 45$ e 60 dias após a realização da enxertia. 5 - O diâmetro do porta-enxerto foi medido com paquímetro digital de $0,001 \mathrm{~mm}$ de precisão, aos 0 ; 30 e 60 dias após a realização da enxertia e a altura de cerca de $1 \mathrm{~cm}$ acima do colo da muda.

\section{RESULTADOS E DISCUSSÃO}

Poderia destacar que, tanto na primeira como na segunda semeadura, dentre os vários portaenxertos, $P$. gibertii e $P$. alata foram o primeiro e o último, respectivamente, a iniciarem a germinação das plântulas. $P$. gibertii iniciou a emergência na primeira semeadura, após 10 dias e, na segunda, com 07 dias. Já $P$. alata iniciou a emergência na primeira semeadura, após 20 dias, e na segunda com 13 dias. Para ambos, o tratamento de pré-embebição em água antecipou o início da emergência das plântulas. Para as demais espécies de porta-enxertos, na primeira semeadura, não se fez o registro do início da emergência. Já na segunda semeadura, observou-se o início da emergência após 08 dias para $P$. edulis f. flavicarpa, P. cincinnata e P. coccínea e, após 12 dias, para $P$. setacea.

As sementes de $P$. caerulea não germinaram na segunda semeadura, embora se tenham usado sementes do mesmo lote em ambas as semeaduras. Isto pode ter ocorrido por perda do poder de germinação, ou por entrada em dormência no período de 37 dias entre as duas semeaduras. Espécies silvestres de passifloras apresentam esse tipo de adaptação e, com isso, seus descendentes têm maior chance de sobrevivência em um período futuro, com condições edafoclimáticas mais favoráveis. $\mathrm{Ou}$, ainda, o tratamento de pré-embebição não foi adequado para esta espécie (MELO, 1999; MELO et al., 2000).

Como pode ser observado na Tabela 1, nas duas semeaduras, as espécies cultivadas ( $P$. edulis f. Alavicarpa e P. alata) apresentaram, no geral, os maiores percentuais de germinação. A exceção entre as espécies silvestres foi $P$. coccinea, que apresentou percentuais de germinação próximos aos das espécies cultivadas, tendo mesmo superado P. alata na segunda semeadura.

Para P. gibertii e P. setacea, a embebição das sementes favoreceu a percentagem de germinação, com aumentos de 21,8\% (aos 22 dias x 44 dias) para P. gibertii e de $135,7 \%$ (aos 22 dias x 44 dias) e de 197,8\% (aos 29 dias x 51 dias) para P. setacea.

Também pode ser observado que a maioria das espécies atingiu o maior percentual de germinação entre 44 e 51 dias após a primeira semeadura, e entre 22 e 29 dias após a segunda. Assim, pode-se dizer que o tratamento de pré-embebição das sementes reduziu praticamente pela metade o tempo necessário para atingir o maior percentual de germinação.

Como pode ser observado na Tabela 2, a morte de plantas só foi constatada 15 dias após a enxertia. Para cinco (P. edulis f. Flavicarpa, $P$. gibertii, $P$. cincinnata, $P$. caerulea e $P$. alata) das sete espécies, o pegamento foi de cerca de $100 \%$, tendo-se perdido uma muda de $P$. caerulea e duas de P. alata, das 36 mudas enxertadas. O pior desempenho da combinação P. setacea comP. edulis f. flavicarpa deveu-se ao fato de que, em virtude do lento desenvolvimento inicial, mesmo que se tenha realizado a enxertia dois meses após as primeiras, a mesma ainda se apresentava muito tenra, e várias plantas sequer suportavam o peso da fita crepe. Também de desenvolvimento lento, a combinação P. coccinea com P. edulis f. flavicarpa, inicialmente, demonstrou bom pegamento, embora esse índice não 
se tenha mantido no período seguinte.

De forma geral, os resultados obtidos para pegamento da enxertia foram superiores aos encontrados na literatura (CORRÊA, 1978; OLIVEIRA et al.,1983; PACE, 1983; SEIXAS et al., 1987; BACCARIN, 1988; MENEZES, 1990; KIMURA, 1994; MENEZES et al., 1994; LIMA et al., 1997; LIMA, 1999; CHAVES et al., 2004). Vale ressaltar a variação de métodos, porta-enxerto e mesmo enxertos encontrados nessa literatura. Também se verifica grande variação no pegamento relatado na literatura, mesmo quando utilizados o mesmo método de enxertia e a mesma combinação enxerto/porta-enxerto (CHAVES et al., 2004; SILVA et al., 2005; JUNQUEIRA et al., 2006).

Em relação à altura de plantas, observouse uma diferença significativa entre as quatro avaliações realizadas $(0 ; 30 ; 45$ e 60$)$ para cada espécie utilizada como porta-enxerto (Tabela 3 ). As alturas de plantas, no momento 0 dia já foi diferente entre as combinações (copa/porta-enxertos) testadas. Analisando-se de forma geral, constatou-se um destaque para o $P$. caerulea, que, mesmo tendo apresentado a terceira média inicial, superou os demais e mostrou, no final, maior velocidade de crescimento em altura. Também se observou a formação de dois grupos distintos, dentro dos quais as alturas medidas pouco diferiram. No primeiro, estavam $P$. caerulea, $P$. gibertii, $P$. cincinnata e $P$. edulis f. flavicarpa, que se pode chamar de espécies como porta-enxertos que induziram maior desenvolvimento inicial à copa, sendo que $P$. cincinnata só induziu na última avaliação (quando se compararam os incrementos). No segundo, encontram-se $P$. alata, $P$. setacea e $P$. coccinea, as espécies de uso como porta-enxertos de menor desenvolvimento inicial.

Merece destaque o fato de que, aos 45 dias após a realização da enxertia, as plantas do grupo de maior desenvolvimento inicial já haviam atingido a altura mínima de $15 \mathrm{~cm}$ (RUGGIERO, 1980; MANICA, 1981; STEINBERG, 1988; SÃO JOSÉ, 1991; LIMA et al., 1994; SÃO JOSÉ et al., 1994; TEIXEIRA, 1994; LIMA, 1999); portanto, aptas para plantio a campo. Somando-se a esses 45 dias, cerca de 40 dias necessários à germinação e desenvolvimento das plântulas para atingirem o estádio fenológico para a execução da enxertia, pode-se dizer que foram necessários 85 dias, ou cerca de três meses, para a obtenção de plantas prontas para o plantio no campo com os portaenxertos de maior desenvolvimento inicial. Esse resultado mostrou uma antecipação da obtenção das mudas em 25 dias, cerca de um mês, em relação aos resultados obtidos por Kimura (1994), trabalhando com os porta-enxertos $P$. caerulea, $P$. gibertii, P. alata e P. foetida. Esse fato, provavelmente, ocorreu por cinco fatores: semeadura realizada em espaçamento suficiente nas bandejas a fim de evitar o estiolamento das plântulas, para elas atingirem o mais rápido possível um diâmetro compatível com a realização da enxertia hipocotiledonar; o substrato utilizado com nutrientes, ao invés de areia lavada; antecipação do estádio fisiológico para a realização da enxertia de 2 a 3 folhas definitivas para apenas 1, totalmente expandida; eliminação do estresse do segundo transplantio, fazendo-se o primeiro logo para recipiente individual, e, embora de forma empírica, a "fertirrigação" realizada nas mudas, aos 30 dias após a enxertia.

Já com os porta-enxertos $P$. setacea e $P$. coccinea, foram necessários cerca de 90 dias para se obterem as primeiras plântulas em condições de serem enxertadas, e é provável que $P$. setacea necessitasse de um tempo ainda maior. Estimando-se que estes dois porta-enxertos mais o P.alata mantivessem o ritmo de crescimento (Tabela 4) observado entre 45 - 60 dias no período seguinte, só aos 75 dias atingiriam a altura recomendada para o plantio a campo. Considerandose ainda que foram necessários cerca de 40 dias da semeadura para a realização da enxertia com o $P$. alata, pode-se dizer que seriam necessários 115 dias ou cerca de quatro meses da semeadura à obtenção de plantas prontas para o plantio a campo com o $P$. alata, e pelo menos 165 dias, ou cinco meses e meio, para obtê-las com as espécies $P$. setacea e P. coccinea.

Observando-se as Tabelas 4 e 5, constata-se que houve diferença significativa para o incremento de altura e diâmetro de cada espécie em relação ao tempo. Inicialmente, a combinação $P$. edulis f. flavicarpa sob P. edulis f. flavicarpa apresentou maior velocidade de crescimento, sendo depois alcançado e até superado pela combinação $P$. gibertii e $P$. caerulea sob $P$. edulis f. flavicarpa. De modo geral, o incremento de altura dobrou no segundo mês. Isso, provavelmente, ocorreu devido ao fato de, no segundo mês, já terem sido vencidos os eventos que envolvem a formação da união da enxertia (soldadura, formação da ponte de calo entre as parte enxertadas e a conexão dos tecidos vasculares); dessa forma, toda a energia excedente para a manutenção dos tecidos da planta estava canalizada para o crescimento vegetativo (RIBEIRO et al., 2008). Da mesma forma, observou-se que geralmente mais que dobrou o incremento de diâmetro no segundo mês, o que pode ser atribuído às mesmas razões expostas anteriormente. Cabe ainda ressaltar o desempenho de $P$. gibertii, $P$. caerulea, $P$. alata e mesmo $P$. setacea, em relação a essa característica. 
$\mathrm{O}$ incremento do número de folhas em relação ao tempo inicial, nas avaliações realizadas, de forma geral, só apresentou diferença significativa para a espécie P. edulis f. flavicarpa (Tabela 6). No primeiro mês após a enxertia, houve um destaque para $P$. cincinnata, seguida por $P$. gibertii, $P$. edulis f. Alavicarpa, P. alata e P. caerulea. Aos 45 dias, houve diferença significativa apenas entre $P$. edulis f. Alavicarpa e P. coccinea. Já aos 60 dias, não houve diferença significativa entre nenhum dos portaenxertos. Assim, deve-se ponderar que o número de intemódios, usado por Staveley e Wolstenholme (1990), é uma característica mais apropriada e menos sujeita a variações, como as relatadas para a avaliação de crescimento dessas plantas, uma vez que não foi utilizada, neste trabalho, por ter sido observada posteriormente à execução.

TABELA 1 - Percentagens de germinação das sementes de sete espécies de passifloras silvestres. JaboticabalSP.

\begin{tabular}{|c|c|c|c|c|c|}
\hline \multicolumn{6}{|c|}{$\left(1^{\text {a }} \text { semeadura }\right)^{1}$} \\
\hline \multirow[b]{2}{*}{ Espécies } & & \multicolumn{3}{|c|}{ Dias após a semeadura } & \multirow[b]{2}{*}{58} \\
\hline & 30 & 37 & 44 & 51 & \\
\hline P.edulis f. flavicarpa & 46,00 & 52,00 & 68,00 & 76,00 & 76,00 \\
\hline P. gibertii & 24,00 & 28,00 & 32,00 & 32,00 & 32,00 \\
\hline P. cincinnata & 20,00 & 32,00 & 32,00 & 33,00 & 33,00 \\
\hline P. caerulea & 42,00 & 55,00 & 55,00 & 55,00 & 55.00 \\
\hline P. alata & 51,00 & 60,00 & 65,00 & 69,00 & 69,00 \\
\hline P. coccinea & 08,00 & 49,00 & 65,00 & 67,00 & 67,00 \\
\hline P. setacea & 08,00 & 13,00 & 14,00 & 22,00 & 28,00 \\
\hline \multicolumn{6}{|c|}{$\left(2^{\mathrm{a}} \text { semeadura }\right)^{2}$} \\
\hline & & \multicolumn{3}{|c|}{ Dias após a semeadura } & \\
\hline Espécies & 08 & 15 & 22 & 29 & 36 \\
\hline P.edulis f. flavicarpa & 8,33 & 53,33 & 58,33 & 58,33 & 63,33 \\
\hline P. gibertii & 15,83 & 31,67 & 39,17 & 39,17 & 39,17 \\
\hline P. cincinnata & 9,17 & 24,17 & 26,67 & 26,67 & 26,67 \\
\hline P. caerulea & 0 & 0 & 0 & 0 & 0 \\
\hline P. alata & 0 & 2,50 & 18,33 & 39,17 & 45,00 \\
\hline P. coccinea & 3,33 & 47,50 & 58,33 & 58,33 & 58,33 \\
\hline P. setacea & 0 & 9,17 & 33,33 & 41,67 & 41,67 \\
\hline
\end{tabular}

1 - Semeadura efetuada em 30-10-2001, com sementes não pré-embebidas.

2 - Semeadura efetuada em 07-12-2001, com sementes pré-embebidas (12 horas).

TABELA 2 - Percentagens de enxertos pegos por enxertia hipocotiledonar em maracujazeiro-amarelo (Passiflora edulis f. flavicarpa) em sete espécies de passifloras silvestres. Jaboticabal - SP.

\begin{tabular}{ccccccccc}
\hline \multirow{2}{*}{ Espécies } & $\mathbf{8}$ & $\mathbf{7}$ Dias após a enxertia \\
\cline { 2 - 9 } & $\mathbf{0 5}$ & $\mathbf{1 0}$ & $\mathbf{1 5}$ & $\mathbf{2 0}$ & $\mathbf{2 5}$ & $\mathbf{3 0}$ & $\mathbf{4 5}$ & $\mathbf{6 0}$ \\
\hline P.edulis f. flavicarpa & 100 & 100 & 100 & 100 & 100 & 100 & 100 & 100 \\
P. gibertii & 100 & 100 & 100 & 100 & 100 & 100 & 100 & 100 \\
P. cincinnata & 100 & 100 & 100 & 100 & 100 & 100 & 100 & 100 \\
P. caerulea & 100 & 100 & 100 & 100 & 100 & 100 & 100 & 97,2 \\
P. alata & 100 & 100 & 100 & 97,2 & 97,2 & 97,2 & 97,2 & 94,4 \\
P. coccinea & 100 & 100 & 100 & 97,2 & 97,2 & 97,2 & 77,8 & 72,2 \\
P. setacea & 100 & 100 & 44,4 & 44,4 & 41,6 & 41,6 & 38,8 & 30,6 \\
\hline
\end{tabular}


TABELA 3 - Altura $(\mathrm{cm})$ de mudas de maracujazeiro-amarelo, em relação à data de enxertia, produzidas por enxertia hipocotiledonar em plântulas de sete espécies de passifloras silvestres. Jaboticabal - SP.

\begin{tabular}{ccccc}
\hline \multirow{2}{*}{ Espécies } & \multicolumn{4}{c}{ Dias após à enxertia } \\
\cline { 2 - 5 } & $\mathbf{0}$ & $\mathbf{3 0}$ & $\mathbf{4 5}$ & $\mathbf{6 0}$ \\
\hline P. caerulea & $8,96 \mathrm{Dab}$ & $11,97 \mathrm{Cab}$ & $17,01 \mathrm{Bab}$ & $23,62 \mathrm{Aa}$ \\
P. gibertii & $10,04 \mathrm{Da}$ & $13,12 \mathrm{Ca}$ & $17,73 \mathrm{Ba}$ & $22,10 \mathrm{Aab}$ \\
P. cincinnata & $9,51 \mathrm{Cab}$ & $11,36 \mathrm{Cb}$ & $15,32 \mathrm{Bb}$ & $18,68 \mathrm{Abc}$ \\
P.edulis f. flavicarpa & $8,49 \mathrm{Db}$ & $12,86 \mathrm{Cab}$ & $16,37 \mathrm{Bab}$ & $18,10 \mathrm{Ac}$ \\
P. alata & $5,48 \mathrm{Dc}$ & $8,41 \mathrm{Cc}$ & $10,42 \mathrm{Bc}$ & $12,00 \mathrm{Ad}$ \\
P. setacea & $6,06 \mathrm{Cc}$ & $8,63 \mathrm{BCc}$ & $10,15 \mathrm{Bc}$ & $12,45 \mathrm{Ad}$ \\
P. coccinea & $5,52 \mathrm{Cc}$ & $7,12 \mathrm{Bc}$ & $8,23 \mathrm{Bc}$ & $11,18 \mathrm{Ad}$ \\
\hline Média & 7,72 & 10,72 & 14,30 & 17,95
\end{tabular}

Médias seguidas de mesma letra, maiúscula na horizontal e minúscula na vertical, não diferem significativamente, pelo teste de Tukey, a $5 \%$.

TABELA 4 - Incremento de altura $(\mathrm{cm})$ de mudas de maracujazeiro-amarelo, em relação à data de enxertia, produzidas por enxertia hipocotiledonar em plântulas de sete espécies de passifloras silvestres. Jaboticabal -SP.

\begin{tabular}{cccc}
\hline Espécies & \multicolumn{3}{c}{ Dias após à enxertia } \\
\hline P. caerulea & $\mathbf{3 0}$ & $\mathbf{4 5}$ & $\mathbf{6 0}$ \\
P. gibertii & $3,01 \mathrm{Cb}$ & $8,09 \mathrm{Ba}$ & $14,84 \mathrm{Aa}$ \\
P.edulis f. flavicarpa & $3,08 \mathrm{Cb}$ & $7,54 \mathrm{Bab}$ & $11,88 \mathrm{Aab}$ \\
P. cincinnata & $4,37 \mathrm{Ca}$ & $7,98 \mathrm{Ba}$ & $9,71 \mathrm{Abc}$ \\
P. alata & $1,85 \mathrm{Ccd}$ & $5,80 \mathrm{Bbc}$ & $9,16 \mathrm{Abcd}$ \\
P. setacea & $2,92 \mathrm{Cbc}$ & $4,91 \mathrm{Bc}$ & $6,58 \mathrm{Ade}$ \\
P. coccinea & $2,57 \mathrm{Bbcd}$ & $4,25 \mathrm{Bcd}$ & $6,68 \mathrm{Ade}$ \\
Média & $1,60 \mathrm{Bd}$ & $2,82 \mathrm{Bd}$ & $5,95 \mathrm{Ae}$ \\
\hline
\end{tabular}

- Médias seguidas de mesma letra, maiúscula na horizontal e minúscula na vertical, não diferem significativamente, pelo teste de Tukey, a $5 \%$.

TABELA 5 - Incremento de diâmetro $(\mathrm{mm})$ de mudas de maracujazeiro-amarelo, em relação à data de enxertia, produzidas por enxertia hipocotiledonar em plántulas de sete espécies de passifloras silvestres. Jaboticabal -SP.

\begin{tabular}{ccc}
\hline Espécies & \multicolumn{2}{c}{ Dias após a enxertia } \\
\cline { 2 - 3 } & $\mathbf{3 0}$ & $\mathbf{6 0}$ \\
\hline P.edulis $\mathrm{f}$. flavicarpa & $0,57 \mathrm{Bab}$ & $1,31 \mathrm{Aab}$ \\
P. gibertii & $0,31 \mathrm{Bab}$ & $1,53 \mathrm{Aa}$ \\
P. alata & $0,34 \mathrm{Bab}$ & $1,21 \mathrm{Aab}$ \\
P. caerulea & $0,07 \mathrm{Bb}$ & $1,40 \mathrm{Aab}$ \\
P. cincinnata & $0,65 \mathrm{Ba}$ & $1,26 \mathrm{Aab}$ \\
P. setacea & $0,14 \mathrm{Bb}$ & $0,90 \mathrm{Aab}$ \\
P. coccinea & $0,22 \mathrm{Bb}$ & $0,80 \mathrm{Ab}$ \\
\hline Média & 0,15 & 1,27 \\
\hline
\end{tabular}

Médias seguidas de mesma letra, maiúscula na horizontal e minúscula na vertical, não diferem significativamente, pelo teste de Tukey, a $5 \%$. 
TABELA 6 - Incremento do número de folhas de mudas de maracujazeiro-amarelo, em relação à data de enxertia, produzidas por enxertia hipocotiledonar em plântulas de sete espécies de passifloras silvestres. Jaboticabal-SP.

\begin{tabular}{llll}
\hline Espécies & \multicolumn{3}{c}{ Dias após a enxertia } \\
\cline { 2 - 4 } & $\mathbf{3 0}$ & $\mathbf{4 5}$ & $\mathbf{6 0}$ \\
\hline P.edulis f. flavicarpa & $3,58 \mathrm{Bab}^{*}$ & $4,18 \mathrm{Aa}$ & $4,20 \mathrm{Aa}$ \\
P. gibertii & $3,60 \mathrm{Aab}$ & $3,72 \mathrm{Aab}$ & $4,00 \mathrm{Aa}$ \\
P. cincinnata & $3,65 \mathrm{Aa}$ & $3,61 \mathrm{Aab}$ & $3,87 \mathrm{Aa}$ \\
P. alata & $3,43 \mathrm{Aab}$ & $3,68 \mathrm{Aab}$ & $3,76 \mathrm{Aa}$ \\
P. setacea & $3,06 \mathrm{Ac}$ & $3,40 \mathrm{Aab}$ & $3,68 \mathrm{Aa}$ \\
P. caerulea & $3,41 \mathrm{Ab}$ & $3,22 \mathrm{Aab}$ & $3,53 \mathrm{Aa}$ \\
P. coccinea & $2,97 \mathrm{Ac}$ & $3,21 \mathrm{Ab}$ & $3,26 \mathrm{Aa}$ \\
\hline Média & 3,42 & 3,75 & 3,68 \\
\hline
\end{tabular}

*Dados transformados er $\sqrt{X+8}$

Médias seguidas de mesma letra, maiúscula na horizontal e minúscula na vertical, não diferem significativamente, pelo teste de Tukey, a $5 \%$.

\section{CONCLUSÕES}

1-O método de enxertia hipocotiledonar utilizado foi bem-sucedido para a maioria das espécies utilizadas e é eficiente para a produção de mudas de maracujazeiro-amarelo.

2-Na fase de produção de mudas, destacaramse como porta-enxertos: as espécies $P$. caerulea, $P$. gibertii, $P$. cincinnata e $P$. edulis f. flavicarpa, tanto pelo excelente índice de pegamento, como pela precocidade de obtenção da muda enxertada pronta para ir ao campo.

\section{REFERÊNCIAS}

BACCARIN, M.N.R.A. Cultura de tecidos e enxertia em Passifíora spp. 1988 101f. Dissertação (Mestrado em Agronomia, Área de Fitotecnia) Escola Superior de Agricultura Luiz de Queiroz, Universidade de São Paulo, Piracicaba, 1988.

CHAVES, R. da C.; JUNQUEIRA, N.T.V.; MANICA, I.; PEIXOTO, J.R.; PEREIRA, A.V.; FIALHO, J.F. Enxertia de maracujazeiro-azedo em estacas herbáceas enraizadas de espécies de passifloras nativas. Revista Brasileira de Fruticultura, Jaboticabal, v.26, n.1, p.120-123, 2004.
CORRÊA, L.S. Contribuição ao estudo da enxertia por garfagem em maracujá (Passiflora edulis Sims f. flavicarpa Deg.) durante a fase de viveiro. 1978. 43 f. Dissertação (Mestrado em Agronomia) - Faculdade de Ciências Agrárias e Veterinárias, Universidade Estadual Paulista, Jaboticabal, 1978.

DELANOË, O. Etude de la résistance de passiflores de Guyane française vis-à-vis de Fusarium pathogènes de la culture dês fruits de la Passion (Passiflora edulis Sims f. flavicarpa). Fruits, Paris, v. 46, n. 5, p. 593-600, 1991.

JUNQUEIRA, N.T.V.; LAGE, D.A. da C.; BRAGA, M.F.; PEIXOTO, J.R.; BORGES, T.A.; ANDRADE, S.R.M. de. Reação a doenças e produtividade de um clone de maracujazeiro-azedo propagado por estaquia e enxertia em estacas herbáceas de Passiflora silvestre. Revista Brasileira de Fruticultura, Jaboticabal, v.28, n.1, p.97-100, 2006.

\section{KIMURA, A. Estudo da enxertia hipocotiledonar} de plântulas em Passiflora edulis Sims f. flavicarpa Deg. 1994. 56f. Monografia (Trabalho de graduação em Agronomia) - Faculdade de Ciências Agrárias e Veterinárias, Universidade Estadual Paulista, Jaboticabal, 1994.

LIMA, A.A. (coord.). O cultivo do maracujá. Cruz das Almas-BA: Embrapa Mandioca e Fruticultura, 1999. 130p. (Circular Técnica, 35). 
LIMA, A.A.; BORGES, A.L; SANTOS FILHO, H.P.; SANTOS, L.B.; FANCELLI, M.; SANCHES, N.F. Instruções práticas para o cultivo do maracujazeiro Cruz das Almas, BA: Embrapa Mandioca e Fruticultura, 1994. 49p. (Circular Técnica, 20).

MANICA, I. Fruticultura tropical: 1. maracujá. São Paulo: Agronômica Ceres, 1981.160p.

LIMA, A.A.; SANTOS FILHO, H.P.; CALDAS, R.C. Porta-enxertos e tipos de enxertia para o maracujazeiro-amarelo. Cruz das Almas-BA: Embrapa Mandioca e Fruticultura, 1997. 3p. (Comunicado Técnico, 50)

LIMA, A.A.; CALDAS, R.C.; CUNHA, M.A. P.; SANTOS FILHO, H.P. Avaliação de porta - enxertos e tipos de enxertia para o maracujazeiro-amarelo. Revista Brasileira de Fruticultura, Jaboticabal - SP, v. 21, n. 3, p. 318-321, 1999.

MELO, A.L. de. Métodos de quebra de dormência, e de armazenamento de sementes, e aspectos de obtenção de mudas de maracujá-suspiro (Passiflora nitida H.B.K.). 1999. 95f. Tese (Doutorado em Agronomia, Área de Produção Vegetal) Faculdade de Ciências Agrárias e Veterinárias, Universidade Estadual Paulista, Jaboticabal, 1999.

MELO, A.L. de; OLIVEIRA, J.C. de; VIEIRA, R.D. Superação de dormência em sementes de $P$. nitida H.B.K. com hidróxido de cálcio, ácido sulfúrico e ácido giberélico. Revista Brasileira de Fruticultura, Jaboticabal, v.22, n.2, 260-263, 2000.

MENEZES, J.M.T. Seleção de porta-enxertos tolerantes à morte prematura de plantas para $\boldsymbol{P}$. edulis Sims f. fíavicarpa Deg. e comportamento de $\boldsymbol{P}$. nitida H.B.K, na região de Jaboticabal. 1990. 73f. Dissertação (Mestrado em Melhoramento Genético Vegetal) - Faculdade de Ciências Agrárias e Veterinárias, Universidade Estadual Paulista, Jaboticabal, 1990.

MENEZES, J.M.T.; OLIVEIRA, J.C. de; RUGGIERO, C.; BANZATTO, D.A. Avaliação da taxa de pegamento de enxertos de maracujá-amarelo sobre espécies tolerantes à ,morte prematura de plantas“. Científica, São Paulo, v. 22, n. 1, p. 95104, 1994.
MENZEL, C.M.; WINKS, C.W.; SIMPSON, D.R. Passionfruit in Queensland 3. Orchard management. Queensland Agricultural Jornal, Brisbane, v. 115, n. 3, p. 155-164, 1989.

OLIVEIRA, J.C.; RUGGIERO, C.; NAKAMURA, K.; BAPTISTA, M. Comportamento de Passiflora edulis enxertada sobre $P$. gibertii N. E. Brow. In: CONGRESSO BRASILEIRO DE FRUTICULTURA, 7., 1983, Florianópolis. Anais... Florianópolis: Sociedade Brasileira de Fruticultura, 1983. p. 989-993.

PACE, C.A.M. Comparação de quatro métodos de enxertia para o 'maracujazeiro-amarelo' Passiflora edulis Sims f. flavicarpa Deg. In: CONGRESSO BRASILEIRO DE FRUTICULTURA, 7., 1983, Florianópolis. Anais... Florianópolis: Sociedade Brasileira de Fruticultura, 1983. p. 983-988.

RIBEIRO, L. M.; PEIXOTO, J. R.; ANDRADE, S. R. M. de; FONSECA, R. S.; VIEIRA, L. M.; PEREIRA, W. V. S. Microenxertia ex vitro para eliminação do vírus CABMV em maracujá-azedo. Pesquisa Agropecuária Brasileira, Brasília, v.43, p.589-594, 2008.

RUGGIERO, C. (Ed.) Cultura do Maracujazeiro. Jaboticabal. FCAVJ/UNESP, 1980. 147p.

SÃO JOSÉ, A.R. Propagação do maracujazeiro. In: SÃO JOSÉ, AR.; FERREIRA, F. R.; VAZ, R. L. (Coord.) A cultura do maracujá no Brasil. Jaboticabal: FUNEP, 1991. p. 25-42.

SÃO JOSÉ, A.R.; SOUZA, I.V.B.; DUARTE FILHO, J.; LEITE, M.J.N. Formação de Mudas de Maracujazeiro. In: SÃO JOSÉ, A.R. (Ed.) Maracujá, produção e mercado. Vitória da Conquista: DFZ/ UESB, 1994. p. 41-48.

SEIXAS, L.F.Z.; OLIVEIRA, J.C.; TIHOHOD, D.; RUGGIERO, C. Comportamento de Passiflora macrocarpa como porta-enxerto para Passiflora edulis Sims f. flavicarpa Deg., cultivado em local com histórico de morte prematura de plantas e nematoides do maracujazeiro. In: CONGRESSO BRASILEIRO DE FRUTICULTURA, 9., 1987, Campinas. Anais... Campinas: Sociedade Brasileira de Fruticultura, 1987. p. 597-601. 
SILVA, F. S.; CORRÊA, L. de S.; BOLLIANI, A.C.; SANTOS, P.C. dos. Enxertia de mesa de P. edulis Sims. f. flavicarpa Deg. Sobre Passiflora alata Curtis, em ambiente de nebulização intermitente. Revista Brasileira de Fruticultura, Jaboticabal, n.1,v.27, p.98-101, 2005.

STAVELEY, G.W.; WOLSTENHOLME, B.N. Effects of water stress on growth and flowering of Passiflora edulis Sims grafted to P. caerulea L. Acta Horticulturae, Wageningen, n. 275, p. 551$558,1990$.

STEINBERG, E. Maracujá: guia prático para um manejo equilibrado. São Paulo: Nobel, 1988. 64p.
STENZEL. N.M.C.; CARVALHO, S.L.C. Comportamento do maracujazeiro-amarelo (Passiflora edulis Sims f. flavicarpa Deg.) enxertado sobre diferentes porta-enxertos. Revista Brasileira de Fruticultura, Cruz das Almas, v.14, n.3, p. 183186, 1992.

TEIXEIRA, C.G. Cultura In: TEIXEIRA, C.G.; CASTRO, J.V.; TOCCHINI, R.P.; NISIDA, A.L.A.C.; HASHIZUME, T.; MEDINA, J.C.; TURATTI, J.M.; LEITE, R.S.S.F.; BLISKA, F.M.M.; GARCIA, E.B.G. Maracujá: cultura, matéria-prima, processamento e aspectos econômicos. Campinas: ITAL, 1994. p. 3-142. 